\title{
Pengaruh Pengalaman Kerja, Promosi Jabatan Dan Pengembangan Karir Terhadap Kepuasan Kerja Karyawan Pada PT. X
}

\author{
Yulainda, Akhirman, Firmansyah Kusasi \\ Fakultas Ekonomi Universitas Maritim Raja Ali Haji, Tanjungpinang, Kepulauan Riau, Indonesia
}

\begin{abstract}
ABSTRAK : Penelitian ini bertujuan untuk mengetahui apakah Pengalaman Kerja, Promosi Jabatan dan Pengembangan karir berpengaruh terhadap Kepuasan Kerja Karyawan pada PT. X. Jenis data yang digunakan adalah data primer dan data sekunder yang diperoleh melalui wawancara, penyebaaran kuesioner dan studi kepustakaan yang pengukurannya menggunakan skala likert dan diolah dengan program SPSS versi 22. Teknik sampel menggunakan nonprobability sampling berjumlah 40 responden yang disebar kepada seluruh karyawan PT.X. Metode analisis data yang digunakan adalah analisis kuantitatif dengan menggunakan uji kualitas data, uji asumsi klasik dan analisis pengujian hipotesis. Hasil penelitian ini menunjukan bahwa : (1) Pengalaman Kerja ada pengaruh signifikan antara variabel Pengalaman Kerja terhadap kepuasan kerja karyawan pada PT. X, (2) Promosi Jabatan ada pengaruh signifikan antara variabel Promosi Jabatan terhadap kepuasan kerja karyawan pada PT. X, dan (3) Pengembangan Karir ada pengaruh signifikan antara variabel Pengembangan Karir terhadap kepuasan kerja karyawan pada PT. X.
\end{abstract}

Kata Kunci: Pengalaman Kerja, Promosi Jabatan, Pengembangan Karir dan Kepuasan Kerja Karyawan.

\begin{abstract}
The purpose of this research is to know whether the Work Experience, Job Promotion and Career Development influence Employee Job Satisfaction at PT. X. The type of data that is used consists of primary data and secondary data, obtained by interview, questionnaire distribution and study of library, which the measurement uses Likert scale, and processed with SPSS version 22 program. The sample technique uses nonprobability sampling totaling 40 respondents distributed to all employees of PT. X. Data analysis method used is quantitative analysis using data quality test, classical assumption test and hypothesis testing analysis. The research results indicate that: (1) Work Experience there is a significant influence between Work Experience variables on employee job satisfaction at PT. X, (2) Position Promotion there is a significant influence between Job Promotion variables on employee job satisfaction at PT. X, and (3) Career Development there is a significant influence between Career Development variables on employee job satisfaction at PT. X.
\end{abstract}

Keywords: Work Experience, Job Promotion, Career Development and Employee Job Satisfaction.

Email Address : yulainda@gmail.com 


\section{PENDAHULUAN}

\section{LATAR BELAKANG MASALAH}

Dalam era globalisasi ini, kemajuan suatu organisasi sangat bergantung pada upaya organisasi tersebut bekerja sama dengan organisasi-organisasi lain baik didalam negara maupun diperingkat global dalam bidang yang menjadi core businessnya. Prestasi organisasi tersebut tidak melebihi prestasi sumber daya manusianya. Oleh karena itu, sumber daya manusia adalah aspek terpenting yang menentukan jatuh bangunnya suatu organisasi dalam banyak keadaan.

Pengalaman yang dapat mempengaruhi tingkah laku organisme dapat dianggap sebagai kesempatan belajar. Hasil belajar dari pengalaman kerja akan membuat orang tersebut kerja lebih efektif dan efesien. Pengalaman akan membentuk pengetahuan dan keterampilan serta sikap yang lebih menyatu pada diri seseorang, jika bidang pekerjaan yang ditangani selama masih bekerja merupakan bidang yang sejenis yang pada akhirnya akan membentuk spesialisasi pengalaman kerja diperoleh selama seseorang bekerja pada suatu perusahaan dari mulai masuk hingga saat ini. Pengembangan karir sebagai kegiatan manajemen SDM pada dasarnya memiliki tujuan untuk dapat memperbaiki dan meningkatkan efektivitas pelaksanaan pekerjaan oleh para pekerja agar semakin mampu memberikan kontribusi terbaik dalam mewujudkan tujuan bisnis organisasi.

Berdasarkan uraian latar belakang diatas maka peneliti tertarik untuk melakukan Penelitian dengan judul "Pengaruh Pengalaman Kerja, Promosi Jabatan dan Pengembangan Karier terhadap Kepuasan Kerja Karyawan pada PT. X".

\section{TUJUAN PENELITIAN}

Tujuan yang hendak dicapai dalam

\section{peneltian ini sebagai berikut.}

1. Untuk mengetahui pengaruh pengalaman terhadap kepuasan kerja karyawan pada PT.X

2. Untuk mengetahui pengaruh promosi jabatan terhadap kepuasan kerja karyawan PT.X

3. Untuk mengetahui pengaruh pengembangan karir terhadap kepuasan karyawan PT.X

4. Untuk mengetahui pengaruh pengalaman kerja, promosi jabatan dan pengembangan karir terhadap kepuasan kerja karyawan PT.X.

\section{KAJIAN PUSTAKA}

\section{Pengalaman Kerja}

Menurut Handoko (2014:24) pengalaman kerja merupakan penguasaan pengetahuan dan keterampilan karyawan yang diukur dari lama masa kerja, tingkat pengetahuan dan keterampilan yang dimiliki karyawan. Pengalaman hanya bisa didapatkan melalui tempat kerja.

\section{Promosi Jabatan}

Menurut Siagian (2010:169) promosi adalah apabila seseorang dipindahkan dari suatu pekerjaan ke pekerjaan lain yang tanggung jawabnya lebih besar, tingkatan hierarki jabatan lebih tinggi, dan penghasilan pun lebih besar.

\section{Pengembangan Karir}

Menurut Sadili Samsudin dalam Yusuf $(2015 ; 177)$ menyatakan pengembangan karir adalah suatu kondisi yang menunjukkan adanya peningkatan status seseorang dalam suatu organisasi pada jalur karier yang telah ditetapkan dalam organisasi yang bersangkutan.

\section{Kepuasan Kerja}

Menurut Mangkunegara (2013;107), 
mengemukakan bahwa kepuasan kerja

berhubungan dengan variabel-variabel

seperti turnover, tingkat absebsi umur tingkat

pekerjaan,dan ukuran organisasi.

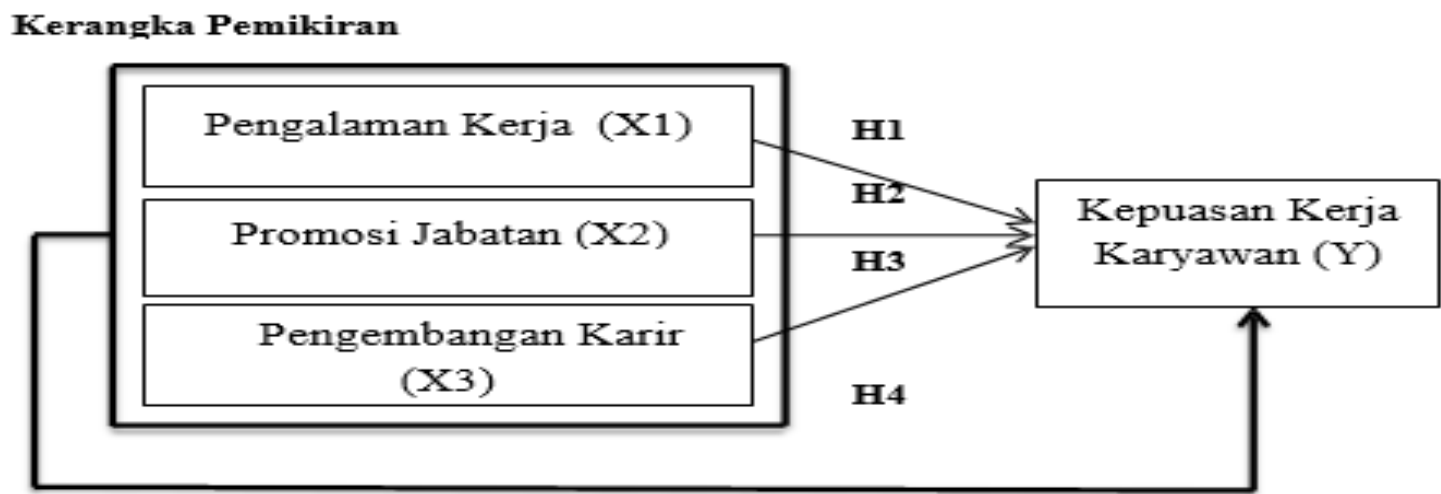

Gambar 2.1

Kerangka pemikiran Penelitian

Berdasarkan uraian kerangka pemikiran dan hasil kajian empiris di atas, maka peneliti mengajukan beberapa hipotesis dalam penelitian ini sebagai berikut:

H1 : Pengalaman Kerja berpengaruh terhadap kepuasan karyawan PT. X

H2 : Promosi Jabatan berpengaruh terhadap kepuasan karyawan PT. X

H3 : Pengembangan Karir berpengaruh terhadap kepuasan karyawan PT. X.

H4 : Pengalaman Kerja, Promosi Jabatan, dan Pengembangan karir secara simultan berpengaruh terhadap kepuasan kerja karyawan berpengaruh terhadap kepuasankaryawan PT. X.

Kepuasan kerja berhubungan dengan turnover mengandung arti bahwa kepuasan kerja yang tinggi selalu dihubungkan dengan turnover yang rendah, dan sebaliknya jika karyawan banyak yang merasa tidak puas maka turnover karyawan tinggi.

\section{BAHAN DAN METODE}

\section{Jenis Penelitian}

Dalam penelitan ini, penulis menggunakan metode penelitian deskriptif kuantitatif, Menurut Sugiono (2015;35) metode penelitian kuantitatif dapat diartikan sebagai metode penelitian yang berlandaskan pada filsafat postpositivisme/enterpretif, digunakan untuk meneliti pada populasi atau sampel tertentu, teknik penggunaan sampel pada umumnya dilakukan secara random, pengumpulan data menggunakan instrument penelitian, analisis data bersifat kuantitatif/statistic dengan tujuan untuk menguji hipotesis yang telah ditetapkan.

\section{Populasi}

Menurut Sugioyono $(2011 ; 80)$ populasi adalah generalisasi yang terdiri atas objek/subjek yang mepunyai kualitas dan karakteristik tertentu yang ditetapkan oleh peneliti untuk dipelajari dan kemudian ditarik kesimpulannya. Populasi dalam penelitian ini adalah karyawan PT Bahtera Bestari Shipping yang berjumlah 40 orang. 


\section{Uji Signifikan Parsial (Uji t)}

\section{Sampel}

Menurut Sugiyono (2011;81) sampel adalah bagian dari jumlah dan karakteristik yang dimiliki oleh populasi tersebut. Bila populasi benar dan peneliti tidak mungkin mempelajari semua yang ada dalam populasi, missal karena keterbatasan dana, tenaga dan waktu, maka peneliti dapat menggunakan sampel yang diambil dari populasi itu

\section{Analisis Regresi Berganda}

Dalam penelitian ini, metode yang digunakan adalah analisis regresi linear berganda. Regresi linear beganda sangat bermanfaat untuk meneliti pengaruh beberapa variabel yang berkorelasi dengan variabel yang diuji.:

Tabel 2. Hasil Uji Analisis Regresi Linear Berganda

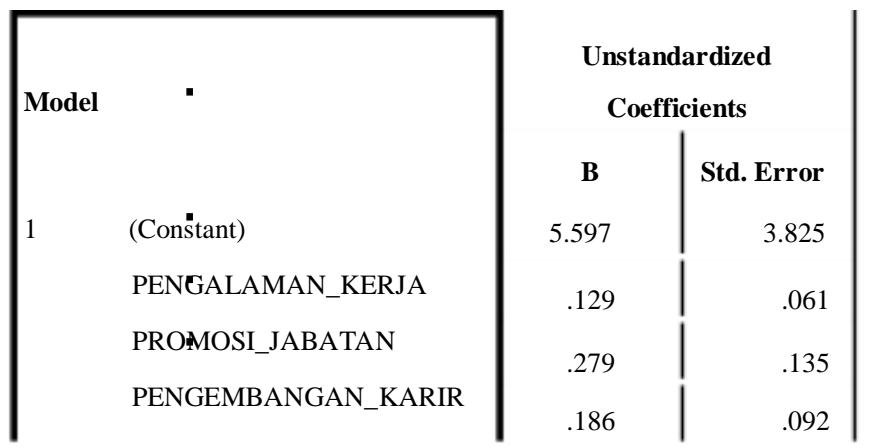

a. Dependent Variable: KEPUASAN_KERJA

Sumber: Hasil Output Data Olahan SPSS

Versi 22

Berdasarkan tabel diatas, ketiga variabel bebas memiliki nilai signifikan dibawah 0.05 , maka dapat disimpulkan bahwa variabel terikat (kepuasan kerja) dipengaruhi oleh ketiga variabel bebas dengan persamaan sebagai berikut ini:

Kepuasan Kerja = $5.597+0.129 \times 1+0.279 \times 2+0.186 \times 3$
Uji t digunakan untuk mengetahui pengaruh masing-masing variabel bebas

(independen) terhadap variabel terikat (dependen) secara parsial.

Tabel 3. Hasil Uji t secara Parsial

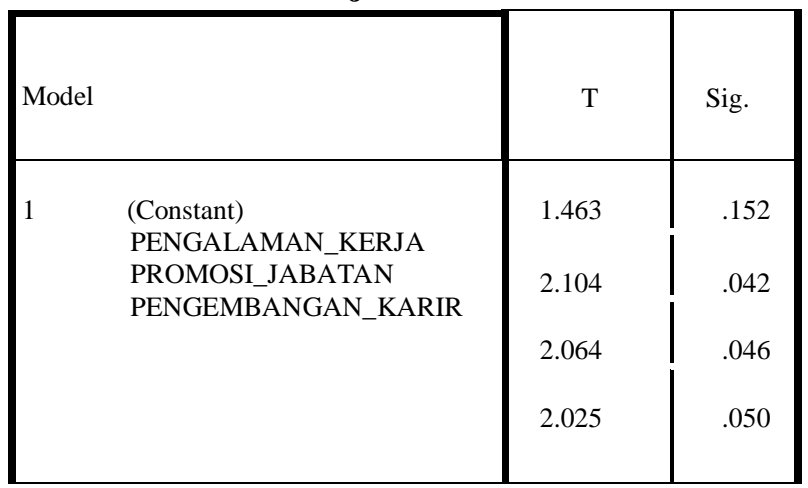

Dari tabel diatas dapat dijelaskan sebagai berikut :

a. Uji Hipotesis 1 (H1)

Berdasarkan hasil pengujian yang telah dilakukan, diperoleh nilai $\mathrm{t}$ hitung untuk variabel pengalaman kerja adalah 2.104 dengan hasil signifikannya $0.042<0.05$ dan didasarkan perbandingan $\mathrm{t}$ hitung dengan $\mathrm{t}$ tabel ( $\mathrm{t}$ tabel $\alpha=0.05$, $\mathrm{df}=40$ ) didapat $\mathrm{t}$ hitung

2.104 lebih besar dari $t$ tabel 1.68595 (2.104 > 1.68595) maka Ho ditolak dan Ha diterima yang menyatakan terdapat pengaruh signifikan pengalaman kerja terhadap kepuasan kerja karyawan.

(H1) : pengalaman kerja berpengaruh signifikan terhadap kepuasan kerja karyawan.

b. Uji Hipotesis $2(\mathrm{H} 2)$

Berdasarkan hasil pengujian yang telah dilakukan, diperoleh nilai $\mathrm{t}$ hitung untuk variabel promosi jabatan 2.064 adalah dengan hasil signifikannya $0.046<0.05$ dan didasarkan perbandingan $t$ hitung dengan $t$ tabel ( $\mathrm{t}$ tabel $\alpha=0.05, \mathrm{df}=40$ ) didapat thitung

2.064 lebih besar dari t tabel 1.68595 
(2.064 > 1.68595) maka Ho ditolak dan Ha diterima yang menyatakan terdapat pengaruh signifikan promosi jabatan terhadap kepuasan kerja karyawan.

(H2) : Promosi jabatan berpengaruh signifikan terhadap kepuasan kerja karyawan.

c. Uji Hipotesis 3 (H3)

Berdasarkan hasil pengujian yang telah dilakukan, diperoleh nilai $\mathrm{t}$ hitung untuk variabel pengembangan karir adalah 2.025 dengan hasil signifikannya $0.025<0.05$ dan didasarkan perbandingan $t$ hitung dengan $t$ tabel (t tabel $\alpha=0.05$, df $=40$ ) didapat thitung 2.025 lebih besar dari t tabel 1.68595 $(2.025>1.68595)$ maka Ho ditolak dan $\mathrm{Ha}$ diterima yang menyatakan terdapat pengaruh signifikan pengembangan karir terhadap kepuasan kerja karyawan diterima.

(H3) : Pengembangan karir berpengaruh signifikan terhadap kepuasan kerja karyawan.

\section{Uji Signifikan Uji F}

Uji statistik $F$ digunakan untuk mengetahui apakah model yang digunakan dalam regresi telah selesai. Uji $F$ juga digunakan untuk mengetahui pengaruh semua variabel independen yang dimasudkan dalam model regresi secara bersama-sama terhadap variabel dependen yang diuji pada tingkat signifikan 0.05 (5\%). Kriteria pengujian uji $\mathrm{F}$ adalah apabila nilai signifikan $\mathrm{F}$ lebih rendah dari 0.05 (5\%), maka dapat disimpulkan bahwa semua variabel independen yang diteliti secara bersama- sama berpengaruh terhadap variabel dependen.
Tabel 4.

Hasil Uji Signifikan Simultan (Uji F)

\begin{tabular}{|lr|r|r|}
\hline Model & & F & Sig. \\
1 & & 6.110 & \multirow{i}{*}{002} \\
& Re & & \\
& gression & &
\end{tabular}

a. Dependent Variable: KEPUASAN_KERJA

b. Predictors: (Constant),

PENGEMBANGAN_KARIR,PENGALAMA N_KERJA PROMOSI_JABATAN

Sumber: Hasil Output Data Olahan SPSS Versi 22

Berdasarkan tabel 4 diatas, dapat disimpulkan bahwa nilai signifikan 0.002 ini berarti nilai sig lebih kecil dari $0.05(0.002<$ 0.005). dan berdasarkan perbandingan $\mathrm{F}$ hitung dengan $\mathrm{F}$ tabel $(\mathrm{F}$ tabel $\alpha=0.05$, df $=$ 40) didapat $F$ hitung 6.110 lebih besar dari $F$ tabel yaitu $2.84(6.110>2.84)$. Maka dalam hal ini Ho ditolak dan Ha diterima. Hal ini hipotesis yang menyatakan bahwa pengalaman kerja, promosi jabatan dan pengembangan karir simultan berpengaruh signifikan terhadap kepuasan kerja karyawan.

\section{Uji Koefisien Determinasi}

Analisis determinasi dalam regresi linear berganda digunakan untuk mengetahui persentase sumbangan pengaruh variabel independen secara serentak terhadap variabel dependen 
Tabel 5. Hasil Uji Koefisien Determinasi

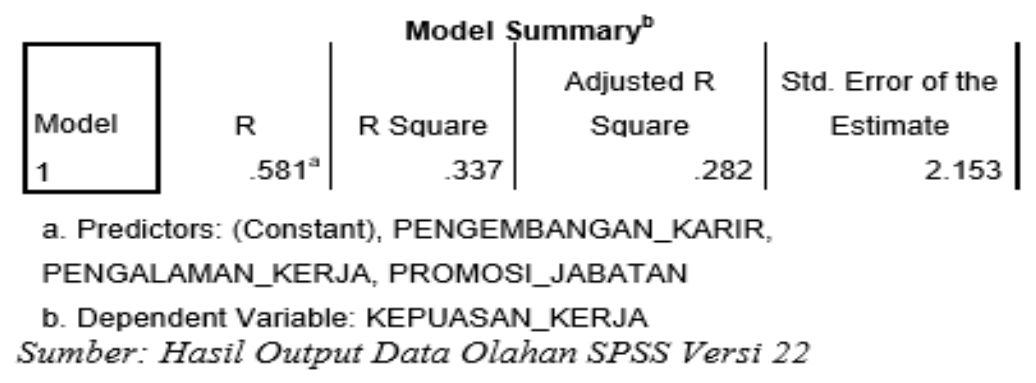

Dari tabel diatas model summary besarnya adjusted $\mathrm{R} 2$ adalah 0.282 , hal ini menunjukan bahwa sebesar $28.2 \%$ kepuasan kerja pada PT. Pelayaran Nasional Bahtera Bestari Shipping dipengaruhi oleh Pengalaman Kerja, Promosi Jabatan dan Pengembangan Karir. Sedangkan sisanya $72.0 \%(100 \%-28.2 \%=72 \%)$, dipengaruhi oleh variabel lain yang tidak dimasukan dalam model penelitian ini.

\section{PEMBAHASAN}

\section{Pengaruh Pengalaman Kerja terhadap Kepuasan Kerja Karyawan}

Berdasarkan hasil penelitian yang dilakukan menunjukkan bahwa pengalaman kerja berpengaruh signifikan terhadap kepuasan kerja karyawan terlihat bahwa terdapat pengaruh antara variabel pengalaman kerja tehadap kepuasan kerja karyawan. dimana dari pengujian hipotesis yang dilakukan dapat dilihat bahwa Ho ditolak dan $\mathrm{H} 1$ diterima. Hal ini menandakan bahwa karyawan lebih mudah melakukan pekerjaan dengan baik karena didukung dari pengalaman kerja. Maka dapat disimpulkan secara parsial bahwa pengalaman kerja berpengaruh terhadap kepuasan kerja karyawan. Hasil penelitian ini sejala dengan hasil penelitian terdahulu yang dilakukan oleh Wijaya (2013) menemukan pengaruh positif dan signifikan antara pengalaman kerja terhadap kepuasan kerja karyawan, dan juga sejalan dengan hasil penelitian Wiguna (2016) menemukan pengaruh positif dan signifikan secara simultan antara pengalaman kerja terhadap kepuasan kerja auditor di Kantor Akuntan Publik Denpasar.

\section{Pengaruh Promosi Jabatan terhadap Kepuasan Kerja Karyawan}

Berdasarkan hasil penelitian yang dilakukan menunjukkan bahwa promosi jabatan berpengaruh signifikan terhadap kepuasan kerja karyawan terlihat bahwa terdapat pengaruh antara variabel promosi jabatan tehadap kepuasan kerja karyawan. .Dimana dari pengujian hipotesis yang dilakukan dapat dilihat bahwa Ho ditolak dan $\mathrm{H} 2$ diterima. Hal ini menandakan bahwa karyawan lebih mudah melakukan pekerjaan dengan baik karena didukung dari promosi jabatan. Maka dapat disimpulkan secara parsial bahwa promosi jabatan berpengaruh terhadap kepuasan kerja karyawan. Hasil penelitian ini sejalan dengan hasil penelitian terdahulu yang dilakukan oleh Setia Jaya (2015) diketahui adanya pengaruh positif dan signifikan promosi jabatan terhadap kepuasan kerja dengan nilai, dan juga sejalan dengan hasil penelitian Andini (2013) diketahui adanya pengaruh positif dan signifikan promosi jabatan terhadap kepuasan kerja karyawan di Kantor Wilayah Dirjen Pajak (DJP) Sumsel dan Kepulauan Bangka Belitung. 


\section{Pengaruh Pengembangan Karir terhadap Kepuasan Kerja Karyawan}

Berdasarkan hasil penelitian yang dilakukan menunjukkan bahwa pengembangan karir berpengaruh signifikan terhadap kepuasan kerja karyawan terlihat bahwa terdapat pengaruh antara variabel pengembangan karir tehadap kepuasan kerja karyawan.. Dimana dari pengujian hipotesis yang dilakukan dapat dilihat bahwa Ho ditolak dan $\mathrm{H} 3$ diterima. Hal ini menandakan bahwa karyawan lebih mudah melakukan pekerjaan dengan baik karena didukung dari pengembangan karir. Maka dapat disimpulkan secara parsial bahwa pengembangan karir berpengaruh terhadap kepuasan kerja karyawan. Hasil penelitian ini sejalan dengan hasil penelitian terdahulu yang dilakukan oleh Lisdiani (2017) diketahui adanya pengaruh positif dan signifikan pengembangan karir terhadap kepuasan kerja, dan sejalan dengan hasil penelitian Minar (2010) diketahui adanya pengaruh positif dan signifikan pengembangan karir terhadap kepuasan kerja karyawan dalam organisasi suatu perusahaan.

\section{Pengaruh Pengalaman Kerja, Promosi Jabatan dan Pengembangan Karir terhadap Kepuasan Kerja Karyawan}

Hasil uji hipotesis keempat (H4) menyatakan bahwa pengalaman kerja, promosi jabatan dan pengembangan karir simultan berpengaruh signifikan terhadap kepuasan kerja karyawan. . Hasil penelitian ini sejalan dengan penelitian terdahulu yang dilakukan oleh Saputra (2017) promosi jabatan memiliki pengaruh positif dan signifikan terhadap kepuasan kerja karyawan, dan selanjutnya hasil penelitian ini sejalan dengan penelitian terdahulu Paramita (2015), Pengembangan karir memiliki pengaruh yang positif dan signifikan terhadap Kepuasan kerja karyawan PT Pos Indonesia (Persero) Bekasi.

\section{KESIMPULAN DAN SARAN \\ Kesimpulan}

Berdasarkan hasil penelitian yang telah dilakukan mengenai pengaruh pengalaman kerja, promosi jabatan dan pengembangan karir terhadap kepuasan kerja karyawan pada PT.X, dapat diperoleh kesimpulan sebagai berikut:

1. Pengalaman Kerja secara signifikan berpengaruh positif terhadap kepuasan kerja karyawan pada PT.X. Berdasarkan hasil pengujian yang telah dilakukan, maka terdapat pengaruh langsung pengalaman kerja terhadap kepuasan kerja karyawan.

2. Promosi Jabatan secara signifikan berpengaruh positif terhadap kepuasan kerja karyawan pada PT.X. Berdasarkan hasil pengujian yang telah dilakukan, maka terdapat pengaruh langsung promosi jabatan terhadap kepuasan kerja karyawan.

3. Pengembangnan Karir secara signifikan berpengaruh positif terhadap kepuasan kerja karyawan pada PT. X. Berdasarkan hasil pengujian yang telah dilakukan, maka terdapat pengaruh langsung pengembangan karir terhadap kepuasan kerja karyawan.

4. Pengalaman Kerja, promosi jabatan dan pengembangan karir secara simultan berpengaruh positif terhadap kepuasan kerja karyawan pada PT. Pelayaran Nasional Bahtera Bestari Shipping. Hal ini, dapat disimpulkan bahwa $\mathrm{H}_{\mathrm{a}}$ diterima dan $\mathrm{H}_{\mathrm{O}}$ ditolak yang menujukkan bahwa penglaman kerja, promosi jabatan dan pengembangan karir secara simultan berpengaruh terhadap kepuasan kerja.

\section{SARAN}

Berdasarkan hasil penelitan dan kesimpulan diatas, maka diberikan saran 
sebagai berikut:

1. Bagi Perusahaan

a. Berdasarkan pembahasan variabel pengalaman kerja menunjukkan bahwa jenjang pengetahun dan tingkat pengalaman kerja diharapkan diutamakan dalam menyeleksi penerimaan karyawan baru agar perusahaan tersebut tidak terkendala dengan pengalaman kerja.

b. Berdasarkan pembahasan variabel promosi jabatan menunjukan bahwa prestasi kerja dan kenaikan jabatan Harus ditingkatkan lagi perusahaan untuk memberikan stimulus berupa penghargaan non finansial bagi karyawan yang memiliki prestasi kerja termasuk mempromosikan karyawan untuk mengisi jabatan tertentu.

c. Berdasarkan pembahasan variabel pengembangan karir menunjukan bahwa promosi karyawan dan kesempatan

berkarir harus ditingkatkan lagi. Jika kinerja karyawan optimal maka akan menguntungkan perusahaan.

\section{Bagi Peneliti Selanjutnya}

Bagi penelitian lain yang hendak melakukan penelitian sejenis agar dapat mengembangkan penelitian serta menambah kekurangan yang ada pada penelitian ini, sehingga makin memperkaya pengetahuan tentang pengaruh pengalaman kerja, promosi jabatan dan pengembangan karir terhadap kepuasan kerja, serta dapat menambahkan variabel lain agar lebih luas lagi dalam penelitian.

\section{DAFTAR PUSTAKA}

Andini, R. (2013). Pengaruh Promosi Jabatan Terhadap Kepuasan Kerja Karyawan Dikantor Wilayah Dirjen Pajak (DJP) Sumsel dan Kepulauan Bangka Belitung . Alumni Fakultas Ekonomi Jurusan Manajemen Universitas
Sriwijaya JEMBATAN - Jurnal Ilmiah Manajemen Bisnis Dan Terapan Tahun X No 1, April 2013.

Handoko, T. H. (2012). Manajemen Personalia dan Manajemen Summber Daya Manusia. Yogyakarta: BPFE UGM.

Lisdiani, V. (2017). Pengaruh Pengembangan Karir terhadap Kepuasan Kerja Karyawan melalui Motivasi Kerja sebagai Variabel Intervening (Studi asus pada Hotel Grasia Semarang) . Administrasi Bisnis, Universitas Diponegoro, Indonesia.

Mangkunegara, A. A. (2013). Manajemen Sumber Daya Manusia Perusahaan. Bandung : Remaja Rosdakarya.

Minar, D. (2010). Pengaruh Sistem Pengkajian Pengembangan Karir dan Promosi Terhadap Kepuasan Kerja Karyawan. Fakultas Ekonomi, Universitas Sangga Buana YPKP, Bandung Jurnal Computech \& Bisnis, Vol. 3, No. 1, Juni 2010,

Paramita, W. (2015). Pengaruh Pengembangan Karir dan Motivasi terhadap Kepuasan Kerja KAryawan pada PT Pos Indonesia (Persero) Bekasi. Universitas Negeri Jakarta.

Priyatno, D. (2013). CAra Kilat Belajar Analisis Data dengan SPSS 20. Yogyakarta: Andi Publisher.

Saputra, I. D. (2017). Pengaruh Promosi Jabatan, Pelatihan dan Lingkungan Kerja terhadap Kepuasan Kerja Karyawan. Universitas Udayana.

Setia Jaya, E. G. (2015). Pengaruh Promosi Jabatan dan Motivasi Kerja terhadap Kepuasan Kerja Agen PT. Asuransi Jiwaraya Magelang Branch Office. Universitas Negeri Yogyakarta .

Siagan, S. P. (2010). Manajemen Sumber

Daya Manusia. Jakarta: PT Bumi

Aksara. Sugiyono. (2011).Statistika 
untuk Penelitian. Bandung: Alfabeta.

\section{(2015). Metode Penelitian}

Manajemen. Bandung: Alfabeta.

Wiguna, I. M. (2016). Pengaruh Tindakan Supervisi, Pengalaman Kerj, Komitmen Organisasi dan Komitmen Profesional terhadap Kepuasan Kerja Auditor. Fakultas Ekonomi Universitas Udayana (Unud), Indonesia ISSN: 2302-8556.

Wijaya1, I. M. (2013). Pengaruh Penempatan dan Pengalaman terhadap Kepuasan dan Kinerja Karyawan. Fakultas Ekonomi Universitas Udayana (Unud), Bali, Indonesia.

Yusuf, B. (2015). Manajemen Sumber Daya Manusia di Lembaga Keuangan Syariah. Jakarta: PT Rajagrafindo Persada. 